\title{
Design and Experimental Study on Dust Collection System of Ceramic Dry Edge Grinding Machine
}

\author{
Junpeng $\mathrm{Li}^{1 \text {, a }}$, Qingchun $\mathrm{Qu}^{2, \mathrm{~b}}$ \\ ${ }^{1}$ Eco-environmental Technology Institute, Guangdong Industry Polytechnic, Guangzhou \\ Guangdong 510300, China
}

${ }^{2}$ Guangzhou Yikang Environmental Protection Equipment Co., Ltd. Guangzhou Guangdong 510880, China

a2006112030@gditc.edu.cn, bqqc1972@139.com

Keywords: ceramic dry edge grinding machine; dust collection; design optimization; experimental study

Abstract. In the process of the dry grinding machine replacing the traditional water grinding machine, the whole solution of the dust collection and recovery system of the ceramic dry edge grinding machine is put forward through the experimental research on the dust property, the wind cooling technology, the dust air force suction, the imbalance of the air volume of the dust intake, the prolongation of the service life of the filter bag and the off-line pulsing ash cleaning technology of the chamber. In the case, the structure design of the dust collector of the ceramic dry grinding machine is improved, and the effect of the bag filter on the high concentration dust waste gas is optimized. The improved dust collection system has high economic and environmental benefits.

\section{Introduction}

The grinding and chamfering production line is one of the essential links in the automatic production line of wall and floor tiles [1]. In recent years, the ceramic industry has gradually used dry grinding machine instead of the traditional water grinding machine. Dry grinding machine has been eroded because of no water, so it is durable, low failure rate, easy to adjust and saves the cost of investment and production. Because of the use of water grinding, the product does not need drying, avoiding discoloration and packing box after packaging. Moldy, recycled dust can also be directly used to enter the ceramic raw material production process [2]. The problem of dry edge grinding machine is dust pollution. Therefore, it is of great significance to develop a high efficiency and energy saving dust collection and recovery system for dry grinding machine. It is of great significance for energy saving and reducing production cost and reducing production cost of ceramic production enterprises.

The bag dust collector is used in the dry dust removal system of the ceramic dry grinding machine. Although the bag dust removal technology is mature, the design of each bag filter needs to be tailored, so it is necessary to improve the structure design of the bag dust collector according to the actual situation [3]. The design principles of the dust collection system of the grinding machine are all very similar, but the poor design of the dust collection is not clean, the life of the filter bag is short, the damage is serious, and the grinding wheel is burnt out. In this paper, the parameters of the bag type dust remover special for the ceramic dry grinding machine are tested and improved in structure. The dust collection and recovery system has the advantages of stable performance, easy operation, energy saving, environmental protection, long life and so on.

\section{Design}

Through the investigation, most of the ceramic manufacturers are equipped with $3 \sim 5$ grinding machines, aiming at the problem of more dust removal equipment. On the basis of the original 1 to 1 , this project has designed a 1 to 5 dust collection and recovery system and a large dust collection and recovery system with 5 grinding machines. In tandem process of flue gas settlement pretreatment and bag type dust removal, the dust particles above $40 \mu \mathrm{m}$ dust are settled first, and the dust particles with 
the remaining particle size less than $40 \mu \mathrm{m}$ are entered into the dust chamber. The dust can be collected through filter bag filtration, and the collected dust can be reused.

From three aspects of technology, equipment and control, the dust collection and recovery system for dry grinding machine for ceramic enterprises is studied and developed. In the process of technology, the series technology of flue settlement pretreatment and bag dust removal in series and wind cooling dry grinding machine are put forward. The 1 to 5 dust collection and recovery system is developed in the equipment. The shell adopts steel plate rolling technology. We have carefully designed and built the equipment strength and appearance; in the control aspect, we have studied and applied the PLC automatic control technology and the off line off-line pulse ash cleaning technology [4].

\section{Experimental}

Wind cooling test. The main problem is to solve the problem of changing from water cooling to wind cooling [5]. There is no precedent in the ceramic industry. Therefore, there is no experience and data in the industry, so it can solve the cooling problem of the grinding wheel and prolong the service life of the grinding wheel, through the suction caliber and the cooling rate of the grinding wheel. Change the number, measure the temperature in the vacuum hood and the life of the grinding wheel to select the appropriate operation parameters. Test data of the wind cooling test of the grinding wheel is shown in Table 1.

Table 1 Wind cooling test data

\begin{tabular}{ccccc}
\hline $\begin{array}{c}\text { Test } \\
\text { number }\end{array}$ & $\begin{array}{c}\text { Suction caliber } \\
(\mathrm{mm})\end{array}$ & $\begin{array}{c}\text { Cooling air volume of } \\
\text { grinding wheel }\left(\mathrm{m}^{3} / \mathrm{h}\right)\end{array}$ & $\begin{array}{c}\text { Temperature in the } \\
\text { suction hood }\left({ }^{\circ} \mathrm{C}\right)\end{array}$ & $\begin{array}{c}\text { Grinding wheel life } \\
(\mathrm{h})\end{array}$ \\
\hline 1 & $\Phi 100$ & 600 & 150 & 12 \\
2 & $\Phi 125$ & 800 & 110 & 15 \\
3 & $\Phi 150$ & 1300 & 80 & 22 \\
4 & $\Phi 200$ & 2300 & 70 & 24 \\
\hline
\end{tabular}

Dust pneumatic conveying test. In order to ensure that all the dust in front of the grinding wheel is sucked away, the ash bucket at the bottom of the edge grinding machine is unblocked and the dust suction inlet is not blocked, the installation position of the suction inlet is very critical. The project group used wind cooling suction caliber $\Phi 200, \mathrm{Q}=2300 \mathrm{~m}^{3} / \mathrm{h}$ to test the location of the suction inlet. The test data is shown in the table 2. According to the test data, the suction inlet is installed in the front side of the ash bucket, which can ensure the normal suction of the dust and not cause the ash bucket blocked.

Table 2 Test data for installation location of the suction inlet

\begin{tabular}{cccc}
\hline $\begin{array}{c}\text { Test } \\
\text { number }\end{array}$ & $\begin{array}{c}\text { Installation location of the } \\
\text { suction inlet }\end{array}$ & Air volume $\left(\mathrm{m}^{3} / \mathrm{h}\right)$ & Test result \\
\hline 1 & Left side of the ash bucket & 2300 & Dust accumulation on the right \\
2 & Right side of the ash bucket & 2300 & Dust accumulation on the left \\
3 & Front of the ash bucket & 2300 & Dust free accumulation
\end{tabular}

Test on imbalance of air volume at the suction inlet. The researchers of the project tested the wind speed and air volume of each suction inlet by the wind speed tester in the field. It was found that the wind speed of the dust suction port near the dust removal equipment was fast, and the wind speed in the dust mouth far from the dust removal equipment was slow. The specific test data is shown in the table 3 . 
Table 3 Test data for wind speed of suction inlet

\begin{tabular}{cccc}
\hline Test location & $\begin{array}{c}\text { Wind speed of suction } \\
\text { inlet }(\mathrm{m} / \mathrm{s})\end{array}$ & $\begin{array}{c}\text { Air volume } \\
\left(\mathrm{m}^{3} / \mathrm{h}\right)\end{array}$ & Test result \\
\hline Front & 20 & 2300 & Dust free accumulation \\
Middle & 18 & 2035 & A small amount of dust accumulation \\
Back & 14 & 1582 & A large amount of dust accumulation
\end{tabular}

According to the test data, the group found that the main reason for the imbalance of air volume is that the wind speed at each suction inlet is equal. In order to get the same amount of wind, the speed of each suction inlet should be equal. The project group has designed the regulating valve at each suction inlet. If the wind speed is too fast, the valve will be regulated smaller to ensure the uniform of wind speed at each suction inlet. Therefore, keeping the wind speed around $20 \mathrm{~m} / \mathrm{s}$, the dust absorption effect is good and the dust bucket has no dust accumulation.

Study on prolonging the service life of filter bag. Because the grinding machine produces a lot of dust when it works. If the dust are all processed through the filter bag, the load of the filter bag is heavy and the filter bag is worn quickly. In order to solve this problem, the system has set up a settlement flue inside the dust collection system, after the dust enters the dust collector, dust with the particle size of $40 \sim 200 \mu \mathrm{m}$ directly settle into the ash bucket by the dust gravity. With no filter bag treatment, the dust concentration is reduced, the life of filter bag is greatly improved. By field test, the concentration of the dust decreased by about $60 \%$ after the settlement of the flue, which greatly reduced the burden of the filter bag and improved the service life of the filter bag. Based on the actual use effect, the filter bag needs to be replaced every two years without the settlement flue. After using the flue, the filter bag is replaced every four years, the life of the filter bag is doubled. In view of the characteristics of ceramic dust, the $550 \mathrm{~g} / \mathrm{m}^{2}$ filter and water repellent and oil protection polyester needle felt material is selected as the filter element of the bag filter.

Test of off-line pulsing ash cleaning technology. Conventional dust removal equipment is on-line cleaning, that is, filter bag in the filter works at the same time also blowing dust, and each line needs a pulse valve to blow. Take the dust removal equipment of 5 edge grinding machines as an example, it needs 80 pulse valves, the air consumption of each pulse valve is $0.1 \mathrm{~m}^{3} / \mathrm{min}$, one cycle period needs air volume $8 \mathrm{~m}^{3} / \mathrm{min}$, and the air consumption is very large. A lot of gas sources are wasted. In addition, the air pressure station of the ceramic factory can only be about $0.4 \mathrm{MPa}$. The pressure of the air cleaning system is low, the dust on the outer surface of the filter bag couldn't be blown down. After the long time, the dust slowly adheres to the filter bag, blocking the filter hole of the filter bag, causing the pressure loss obviously increased, the dust of the grinding machine is escaped. The amount of cold air is not enough for the grinding wheels, and cause them burnout because of high temperature.

In order to solve this problem, the project group reformed the dust removal equipment on the basis of the original on-line ash cleaning [6]. The original on-line cleaning is changed to off-line ash cleaning. The dust removal equipment is divided into 8 chambers from 1 rooms, and the pulse valve is adjusted from 80 valves to 8 valves, and the off-line blowing is carried out separately to each chamber. When the first room needs cleaning, the valve is closed in the first room, so that the room can be cleaned when the room is not working. The dust removal on the outer surface of the filter bag is completely clean, and the effect of the dust cleaning is good. The consumption of gas is adjusted from 80 times of valve $8 \mathrm{~m}^{3} / \mathrm{min}$ to 8 valve times $2 \mathrm{~m}^{3} / \mathrm{min}$, which saves $75 \%$ gas consumption. The bag dust collector adopts the off-line cleaning method, the dust on the outer surface of the filter bag is clean and unblocked by the equipment for a long time, the grinding machine works stably and the dust is all recovered by the dust removal equipment. The phenomenon of dust escape no longer appears. 


\section{Conclusions}

The dust collection system of ceramic dry edge grinding machine uses wind cooling technology, flue settlement pretreatment technology, separated room off-line pulse ash cleaning technology and 1 collection system to 5 grinding machines. The emission of dust concentration of bag filter is less than $30 \mathrm{mg} / \mathrm{Nm}^{3}$, meets the national emission standard, and the dust concentration of the workplace is less than $10 \mathrm{mg} / \mathrm{Nm}^{3}$,reaches the national standard. The trapping rate of the powder suction hopper in the inlet of the dry edge grinding machine is over $95 \%$, about $5 \%$ of the large particles are deposited at the bottom hopper. The normal life of the shell of the dust removal equipment is 15 years. The filter bag is replaced in four years, and the life span is greatly prolonged. The research, application and industrialization of this dust collection system have great economic and social benefits.

\section{Acknowledgements}

This work was financially supported by the Education and Teaching Reform Foundation of Guangdong Industry Polytechnic (JG201711).

\section{References}

[1] X.P. Zhan: Foshan Ceramics Vol. 27 (2014), p. 21.

[2] Y.C. Wong, J. Jia: Ceramics Vol. 6 (2014), p. 27.

[3] L. Qian, Y.Zhu: Industrial Safety and Environmental Protection Vol. 37 (2011), p. 23.

[4] Q.G. Ge, T.Z. Liu: Shandong Chemical Industry Vol. 42 (2013), p. 118.

[5] Y.B. Wong, X.F. Wong, F. Blaabjerg: IEEE Trans Ind Electron Vol. 64 (2016), p. 806.

[6] J. Suh, Y. Lim, J. Zhu : Korean Journal of Chemical Engineering Vol. 28 (2011), p. 613. 